\title{
Effects of Maternal Suicidal Ideation on Child Cognitive Development: A Longitudinal Analysis
}

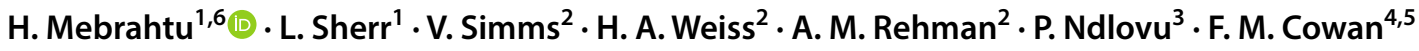

Published online: 29 January 2020

(c) The Author(s) 2020

\begin{abstract}
This study aimed to assess the association between suicidal ideation among mothers living with HIV in Zimbabwe and the cognitive development of their children. Participants were mother-child dyads recruited from two rural districts in Zimbabwe. Data were collected at baseline and 12 months follow-up. Suicidal ideation was assessed using item-10 from the Edinburgh postnatal depression scale. Mixed-effects linear regression was used to assess the association of child cognitive outcomes at follow-up (using the Mullen scales of early learning) with maternal suicidal ideation. Mothers with suicidal ideation at baseline $(\mathrm{n}=171)$ tended to be younger, unmarried, experienced moderate to severe hunger, had elevated parental stress and depression symptoms compared with non-suicidal mothers $(\mathrm{n}=391)$. At follow-up, emerging maternal suicidal ideation was associated with poorer child cognitive outcomes (adjusted mean difference $-6.1 ; 95 \% \mathrm{CI}-10.3$ to $-1.8 ; \mathrm{p}=0.03$ ). Suicidal ideation affects child cognitive development and should be addressed, particularly in HIV positive mothers.
\end{abstract}

Keywords Maternal mental health $\cdot$ HIV/AIDS $\cdot$ Child development $\cdot$ Suicidal ideation $\cdot$ Africa

\section{Introduction}

Suicidal ideation may precede suicide planning and attempted suicide and is a distressing psychological phenomenon, indicative of low mood and poor quality of life [1]. Despite advances in HIV treatment, suicidality (which includes suicidal ideation, suicide attempts, and completed suicides), remains elevated for people living with HIV (PLWH) in comparison with their HIV negative counterparts [2]. Although suicidal ideation is not always an automatic

H. Mebrahtu

helen.mebrahtu.15@ucl.ac.uk

1 Institute of Global Health, University College London, London, UK

2 MRC Tropical Epidemiology Group, School of Hygiene and Tropical Medicine, London, UK

3 World Education Inc./Bantwana (WEI/B), Harare, Zimbabwe

4 Centre for Sexual Health HIV/AIDS Research (CeSHHAR) Zimbabwe, Harare, Zimbabwe

5 Department of International Public Health, Liverpool School of Tropical Medicine, Liverpool, UK

6 Institute of Global Health, University College London, Royal Free Hospital Campus, Rowland Hill St, London NW3 2PF, UK determinant for suicidal behaviour, it is an important risk factor that requires early detection and a potential trigger for intervention [3]. Risk factors for suicidal ideation in PLWH in sub-Saharan Africa (SSA) include younger age [3, 4], being unmarried and depression $[4,5]$. Suicidal ideation among PLWH has also been linked to other factors such as lack of social support [4, 6], fear of HIV status disclosure and stigmatization [7]. Poverty further exacerbates the mental health burden among PLWH particularly in resource limited settings [8]. Increased negative life events and the associated stress in addition to food insecurity all increased the risk of suicidality in studies from Uganda, Peru, and Ethiopia [9-11]. Another study investigating predictive models for suicidal ideation and attempted suicide among women living with HIV in the US found that AIDS diagnosis, physical or sexual abuse, unemployment, and children were all significant predictors of suicide ideation and attempts [12].

There is evidence in the literature that shows child development is affected by maternal mental health [13], with exposure to maternal depression and stress having a negative influence on child development and being associated with impaired cognitive performance [14-16]. Infants of depressed mothers tend to show fewer affectively positive facial expressions and vocalization, more withdrawal, less attentiveness to the mother, decreased activity level, 
greater fussiness, and overall less engagement with people and objects [17]. Studies of suicide ideation specifically show maternal suicidal ideation is associated with poorer mother-infant relationship, and consequently negatively impacts infant development $[17,18]$. In the long term, the quality of the early mother-infant relationship appears to predict aspects of child development, such as diverse forms of psychopathology, behavioural problems, and disruptions in cognitive abilities $[19,20]$. In addition to this, the literature shows clear evidence of developmental delay for children in the presence of HIV infection and HIV exposure [21-23].

Nonetheless, current literature lacks clarity on the relationship between maternal suicidal ideation or behaviour on the child's cognitive development, specifically in the context of HIV and in low resource settings. There is an urgent need for more evidence from low- and middle-income countries investigating the impact of suicidal ideation for mothers living with HIV over a period of time on child cognitive outcomes, especially during the early stages of development. This study uses longitudinal data to investigate the association of maternal suicidal ideation and child cognitive outcome in Zimbabwe, where there is recorded high HIV infection rates as well as elevated mental health burdens generally [13, 24-27], and suicidal challenges specifically.

\section{Methods}

Data were collected for the cluster-randomized controlled trial (The Child Health Initiative for Developmental Outcomes-CHIDO [PACTR201701001387209]) [28]. Details of the trial methods have been published previously [28]. In brief, the aim was to determine the effectiveness of a combined parenting and income-generating programme delivered to caregivers living with HIV and their children aged 0-24 months at recruitment, on global child development in Zimbabwe.

\section{Study Design and Sample}

Mother-child dyads were recruited from catchment areas surrounding 30 clinics in 2 rural districts in Mashonaland East Province. Trial clinics were randomized to the CHIDO intervention or Zimbabwe Ministry of Health and Child Care standard of care, and participants were enrolled in the arm to which their clinic was randomized. Participants in the standard care arm received the recommended standard of care for HIV positive mothers and their HIV exposed or infected children. Participants enrolled in the trial were assessed at baseline and followed up for 12 months for reassessment. This analysis was confined to biological mothers only and their children who completed both assessments. All participants were provided with full information and gave consent to participate in the study as well as consent for child participation.

\section{Measures}

Socio-demographic information was collected on participant characteristics (age, marital status), and socio-economic factors (educational level, employment status, asset index score, and number of adults living in the household), using interviewer-administered questionnaires. All children had an HIV test at follow-up.

A subset of questions from the household food insecurity access scale [29] were used to categorize participants as living: (i) food secure (rarely worried about food access or quality), (ii) moderately food insecure (sometimes i.e. 3-10 times in the last month, worried about food access or quality), or (iii) severely food insecure ( $\geq 1$ household member going to bed hungry or often worrying about food access or quality).

The Edinburgh postnatal depression scale (EPDS), a postpartum depression-screening questionnaire that has been validated for use in Zimbabwe [30, 31], was administered to participating mothers. The EPDS comprises 10 questions that generate scores ranging from 0 to 30 . A cut-off point of (12) which indicates concern for referral was used at baseline [30, 32]. The EPDS score was further categorized into none or minimal (EPDS scores 0-6), mild (EPDS scores 7-13), moderate (EPDS scores 14-19) and severe depression (EPDS scores 20-30) [33]; assessing the severity of maternal depressive symptoms for this population. The suicidal ideation item (item-10) was excluded from the total score.

Suicidal ideation was measured as thoughts of self-harm during screening using a self-reported questionnaire based on the EPDS [30,31]. The EPDS scale contains a specific target item (item-10 "The thought of harming myself has occurred to me") which assesses suicidal ideation [34-36] with good sensitivity (77\%) and specificity (92\%) according to previous studies in South Africa [2, 37]. Those responding "Yes, quite often", "Sometimes" and "Hardly ever" in the past week were coded as experiencing suicidal ideation, whereas those to respond "Never" were coded as not experiencing suicidal ideation. Longitudinal data was utilised to categorise suicidal ideation over time into four groups. Women who did not report suicidal ideation at both baseline and 12 months follow-up were grouped as nonsuicidal. Women reporting suicidal ideation at baseline but not at 12 months follow-up were grouped as improving and women who did not experience suicidal ideation at baseline but did at 12 months were referred to as the emerging suicidal ideation group. Whereas women who experienced 
suicidal ideation at both baseline and 12 months follow-up were marked as the chronic suicidal ideation group.

Parental stress index-short form (PSI-SF), a self-completed screening tool used for identifying different types of stress associated with parenting, was administered to participants [38]. Common mental disorders (CMDs) were assessed using the locally developed and validated Shona symptom questionnaire (SSQ)-8 [39]. The short form is derived from the longer SSQ-14 version. Scores range from 0 to 8 , and scores $\geq 6$ were used as a cut-off point for CMD symptoms.

Child cognitive development was assessed using the Mullen scales of early learning [40, 41]. The Mullen scale is a comprehensive measure that assesses a child's abilities in five developmental domains from birth through 68 months: gross motor skills, visual reception, fine motor skills, receptive language, and expressive language [40]. The Mullen scales were administered to all children by trained assessors in a standardized format at enrolment and 12 months later [28]. The number of assessors was kept to a minimum to maximize the reliability of measurement. Test scores were transformed into an age-standardized T-score, using a US reference population as there was no local Zimbabwean reference population on this index. Four components-the fine motor, expressive language, receptive language, and visual perception scales-were combined to produce the age-standardized early learning composite (ELC) score of general cognitive functioning. The gross motor scale was not included in the ELC score and was used separately [40, 42].

\section{Data Analysis}

To compare the characteristics of participants by suicidal ideation, descriptive analyses were used to summarise the baseline characteristics. Logistic regression was used to identify risk factors associated with suicidal ideation at baseline and was reported using odds ratio (OR) and $95 \%$ confidence intervals (95\% CIs).

Data were pooled for this analysis as there was no evidence of a difference in child cognitive outcomes by trial arm. Mixed-effects linear regression was used to compare child cognitive outcomes by maternal suicidal ideation over 12 months. Mean children's cognitive scores at follow-up by mother's suicidal ideation categories were presented as adjusted mean differences (aMDs). Confounding variables associated with both exposure (maternal suicidal ideations) and outcome (child cognitive scores) in bivariate analyses (at $\mathrm{p}<0.2)$ were included in the multivariable model. Clustering by study sites was accounted for by incorporating a random effect for clinic in all models. A priori adjustments included baseline child Mullen scores, mother's age and the code for the person conducting
Mullen assessments. All analyses were conducted using STATA v.15.1 (StataCorp LP, College Station, Texas, USA).

\section{Ethical Approval}

The trial has been approved by the Medical Research Council of Zimbabwe (MRCZ/A/1943), University College London (6789/002) and the London School of Hygiene and Tropical Medicine (9912).

\section{Results}

\section{Sample Characteristics at Baseline}

The prevalence of suicidal ideation at baseline by demographic, socioeconomic, reproductive and mental health characteristics is shown in Table 1.

At baseline, from the 574 participants enrolled, all 562 biological mothers completed the mental health assessments (the remaining 12 were other primary caregivers). The mean age of the mothers was 31.5 years $(\mathrm{SD}=6.3)$, over half $(53.6 \%)$ had secondary school and above level of education, over three quarters were married $(79.7 \%)$, and $36.7 \%$ reported being formally or informally employed. The mean household size was $5.2(\mathrm{SD}=1.7)$, and $37.7 \%$ of the households reported experiencing moderate to severe hunger. Over half of the women $(55.5 \%)$ were diagnosed with HIV before their pregnancy and were aware of their status prior to conception. HIV status was ascertained for 493 children at follow-up and of these 15 (3.0\%) were HIV positive.

There was no evidence of differences by trial arm in baseline prevalence of suicidal ideation among HIV positive mothers $(53.2 \%$ suicidal ideation in the intervention arm vs. $46.8 \%$ control arm; $\mathrm{p}=0.13$ ). Suicidal ideation was associated with mother's age, marital status, household size, food insecurity, parental stress and depression symptoms (Table 1). Mothers with suicidal ideation were likely to be slightly younger (mean age 30.7 vs. 31.9 ; $\mathrm{p}=0.05$ ), unmarried $(34.2 \%$ vs. $14.3 \%$; p < 0.01$)$, lived in households that experience moderate to severe hunger $(53.8 \%$ vs. $30.7 \%$; p < 0.01), have elevated parental stress (PSI-SF mean -91.9 vs. $81.8 ; \mathrm{p}<0.01)$ and depression symptoms (EPDS mean -14.6 vs. 9.3 ; p < 0.01) compared to the nonsuicidal group. Mothers with suicidal ideation were also more likely to experience severe depression (OR 16.8; $95 \%$ CI 4.5 to $62.3 ; \mathrm{p}<0.01$ ) and CMD symptoms (OR 5.5; $95 \%$ CI 2.9 to $10.5 ; \mathrm{p}<0.01)$ compared to the non-suicidal group (Table 2). 
Table 1 Maternal demographic, socioeconomic, reproductive, mental health characteristics and child cognitive development by suicidal ideation at baseline

\begin{tabular}{|c|c|c|c|c|}
\hline & Non-suicidal $(\mathrm{n}=391)$ & Suicidal $(\mathrm{n}=171)$ & Total $(\mathrm{n}=562)$ & Test, p-value \\
\hline Trial arm, n (\%) & & & & $\mathrm{Chi}^{2}=2.28, \mathrm{p}=0.13$ \\
\hline Intervention & $181(46.3)$ & $91(53.2)$ & $272(48.4)$ & \\
\hline Control & $210(53.7)$ & $80(46.8)$ & $290(51.6)$ & \\
\hline Age (years), mean (SD) & $31.9(6.3)$ & $30.7(6.2)$ & $31.5(6.3)$ & $\mathrm{T}=1.97, \mathrm{p}=0.05$ \\
\hline Education level (completed secondary school and above), n (\%) & $218(55.8)$ & $83(48.5)$ & $301(53.6)$ & $\mathrm{Chi}^{2}=2.49, \mathrm{p}=0.11$ \\
\hline Relationship status ${ }^{\mathrm{a}}, \mathrm{n}(\%)$ & & & & $\mathrm{Chi}^{2}=31.98, \mathrm{p}<0.01$ \\
\hline Married & $335(85.7)$ & $112(65.9)$ & 447 (79.7) & \\
\hline Divorced/separated & $33(8.4)$ & $41(24.1)$ & $74(13.2)$ & \\
\hline Widowed & $14(3.6)$ & $13(7.7)$ & $27(4.8)$ & \\
\hline Never been married & $9(2.3)$ & $4(2.4)$ & $13(2.3)$ & \\
\hline Employment status (yes-employed), n (\%) & $146(37.3)$ & $60(35.1)$ & $206(36.7)$ & $\mathrm{Chi}^{2}=0.26, \mathrm{p}=0.61$ \\
\hline $\begin{array}{l}\text { Household size (number of people living under the same roof), } \\
\text { mean (SD) }\end{array}$ & $5.1(1.6)$ & $5.4(1.9)$ & $5.2(1.7)$ & $\mathrm{T}=-2.35, \mathrm{p}=0.02$ \\
\hline Hunger scales, $\mathrm{n}(\%)$ & & & & $\mathrm{Chi}^{2}=27.05, \mathrm{p}<0.01$ \\
\hline Little to no hunger & $271(69.3)$ & $79(46.2)$ & $350(62.3)$ & \\
\hline Moderate to severe hunger & $120(30.7)$ & $92(53.8)$ & $212(37.7)$ & \\
\hline Asset Index score (terciles) ${ }^{\mathrm{b}}, \mathrm{n}(\%)$ & & & & $\mathrm{Chi}^{2}=3.52, \mathrm{p}=0.17$ \\
\hline Low & $126(32.2)$ & $63(36.8)$ & 189 (33.6) & \\
\hline Middle & $126(32.2)$ & $61(35.7)$ & $187(33.3)$ & \\
\hline High & 139 (35.6) & $47(27.5)$ & $186(33.1)$ & \\
\hline Tested for HIV, n (\%) & & & & $\mathrm{Chi}^{2}=0.94, \mathrm{p}=0.33$ \\
\hline Before pregnancy & $214(54.7)$ & $86(50.3)$ & $300(53.4)$ & \\
\hline During or following pregnancy & $177(45.3)$ & $85(49.7)$ & $262(46.6)$ & \\
\hline Child age (months), mean (SD) & $11.8(6.5)$ & $12.3(6.5)$ & $11.9(6.5)$ & $\mathrm{T}=-0.87, \mathrm{p}=0.38$ \\
\hline \multicolumn{5}{|l|}{ HIV status of child, n (\%) } \\
\hline HIV positive & $8(2.0)$ & $7(4.1)$ & $15(2.7)$ & - \\
\hline HIV exposed and negative & $329(84.1)$ & $149(87.1)$ & $478(85.1)$ & - \\
\hline HIV exposed, status unknown & $54(13.8)$ & $15(8.8)$ & $69(12.3)$ & - \\
\hline \multicolumn{5}{|l|}{ Child cognitive development (Mullen scales), mean (SD) } \\
\hline Expressive language & $53.2(10.6)$ & $52.3(11.0)$ & $52.9(10.7)$ & $\mathrm{T}=0.97, \mathrm{p}=0.33$ \\
\hline Receptive language & $47.7(11.3)$ & $47.7(12.0)$ & $47.7(11.5)$ & $\mathrm{T}=-0.02, \mathrm{p}=0.99$ \\
\hline Fine motor & $50.9(11.0)$ & $50.5(12.3)$ & $50.8(11.4)$ & $\mathrm{T}=0.31, \mathrm{p}=0.76$ \\
\hline Gross motor & $50.9(10.7)$ & $49.7(11.3)$ & $50.5(10.9)$ & $\mathrm{T}=1.20, \mathrm{p}=0.23$ \\
\hline Visual reception & $53.3(12.2)$ & $52.7(13.8)$ & $53.1(12.7)$ & $\mathrm{T}=0.49, \mathrm{p}=0.62$ \\
\hline Early learning composite score & $102.7(17.1)$ & $102.0(19.7)$ & $102.5(17.9)$ & $\mathrm{T}=0.46, \mathrm{p}=0.65$ \\
\hline \multicolumn{5}{|l|}{ Parental stress index, mean (SD) } \\
\hline Parental distress & $30.1(6.9)$ & $36.1(7.4)$ & $31.9(7.6)$ & $\mathrm{T}=-9.22, \mathrm{p}<0.01$ \\
\hline Difficult child & $27.6(6.3)$ & $29.7(7.1)$ & $28.2(6.6)$ & $\mathrm{T}=-3.66, \mathrm{p}<0.01$ \\
\hline Parent-child dysfunction & $24.0(5.8)$ & $26.1(6.4)$ & $24.6(6.0)$ & $\mathrm{T}=-3.81, \mathrm{p}<0.01$ \\
\hline Total stress score & $81.8(15.0)$ & $91.9(17.0)$ & $84.8(16.3)$ & $\mathrm{T}=-6.97, \mathrm{p}<0.01$ \\
\hline Maternal depression scores (EPDS), mean (SD) & $9.3(5.7)$ & $14.6(5.0)$ & $10.9(6.0)$ & $\mathrm{T}=-10.48, \mathrm{p}<0.01$ \\
\hline Maternal depression scores-EPDS, n (\%) & & & & $\mathrm{T}=88.94, \mathrm{p}<0.01$ \\
\hline None & $139(35.6)$ & $12(7.0)$ & $151(26.9)$ & \\
\hline Mild & $149(38.1)$ & $55(32.2)$ & $204(36.3)$ & \\
\hline Moderate & $91(23.3)$ & $72(42.1)$ & $163(29.0)$ & \\
\hline Severe & $12(3.1)$ & $32(18.7)$ & $44(7.8)$ & \\
\hline SSQ-8, mean (SD) & $3.6(2.3)$ & $6.3(1.7)$ & $4.4(2.5)$ & $\mathrm{T}=-13.35, \mathrm{p}<0.01$ \\
\hline SSQ-8 (using $\geq 6$ as cut off), $n$ (\%) & & & & $\mathrm{Chi}^{2}=93.00, \mathrm{p}<0.01$ \\
\hline No CMD symptoms (scores $0-5$ ) & $286(73.2)$ & $51(29.8)$ & $337(60.0)$ & \\
\hline CMD symptoms (scores 6-8) & $105(26.9)$ & $120(70.2)$ & $225(40.0)$ & \\
\hline
\end{tabular}

EPDS the Edinburgh postnatal depression scale, SSQ Shona symptom questionnaire, $C M D$ common mental disorder

${ }^{a}$ Relationship status variable was recoded to married/not married during analysis 
Table 1 (continued)

${ }^{\mathrm{b}}$ Several indicators were used for generating the asset index score including participants education level, number of people living in the same household, source of drinking water, employment status of mother and partner (if they had one), amount of money earned each month and a range of household items (such as electricity, refrigerator, bicycle, cell phone, television etc.)

Table 2 Logistic regression model of risk factors associated with maternal suicidal ideation at baseline $(\mathrm{n}=562)$

\begin{tabular}{|c|c|c|c|}
\hline & $\mathrm{N}$ & Odds ratio $(95 \% \mathrm{CI})$ & $\mathrm{p}$ value \\
\hline \multicolumn{4}{|l|}{ Age group (years) } \\
\hline $16-19$ & 16 & Ref & \\
\hline $20-30$ & 216 & $4.2(0.8$ to 21.2$)$ & 0.08 \\
\hline $31-40$ & 282 & $2.1(0.4$ to 10.7$)$ & 0.35 \\
\hline $41-49$ & 48 & $1.1(0.2$ to 6.4$)$ & 0.92 \\
\hline $50-70$ & - & - & - \\
\hline \multicolumn{4}{|l|}{ Married } \\
\hline No & 115 & Ref & \\
\hline Yes & 447 & $0.2(0.1$ to 0.4$)$ & $<0.01$ \\
\hline \multicolumn{4}{|c|}{ Number of people living in the household } \\
\hline $2-3$ & 83 & Ref & \\
\hline $4-6$ & 375 & $1.4(0.6$ to 3.2$)$ & 0.40 \\
\hline $7-9$ & 95 & $1.4(0.5$ to 3.7$)$ & 0.55 \\
\hline $10-13$ & 9 & $3.8(0.5$ to 28.1$)$ & 0.20 \\
\hline \multicolumn{4}{|l|}{ Hunger scale } \\
\hline Little to no hunger & 350 & Ref & \\
\hline Severe to moderate hunger & 212 & $3.2(1.9$ to 5.6$)$ & $<0.01$ \\
\hline \multicolumn{4}{|c|}{ Maternal depression (EPDS category) } \\
\hline None & 151 & Ref & \\
\hline Mild & 204 & $2.5(1.1$ to 5.8$)$ & 0.04 \\
\hline Moderate & 163 & $2.7(1.1$ to 6.7$)$ & 0.03 \\
\hline Severe & 44 & $16.8(4.5$ to 62.3$)$ & $<0.01$ \\
\hline \multicolumn{4}{|l|}{ SSQ-8 } \\
\hline No CMD symptoms & 337 & Ref & \\
\hline CMD symptoms & 225 & $5.5(2.9$ to 10.5$)$ & $<0.01$ \\
\hline
\end{tabular}

OR odds ratio, EPDS the Edinburgh postnatal depression scale, $S S Q$ Shona symptom questionnaire, $C M D$ common mental disorder

\section{Suicidal Ideation over Time}

After 12 months 514 participants completed a follow-up survey, but only $485(86.3 \%)$ pairs were both completed by the child's biological mother. Of the 485 mothers, $86(17.7 \%)$ reported suicidal ideation at both timelines (chronic), 66 (13.6\%) had suicidal ideation at baseline but not at 12 months follow-up (improvers); 46 (9.5\%) mothers reported emerging suicidal ideation at 12 months only. The largest group $(n=287 ; 59.2 \%)$ did not report suicidal ideation at either time points.

Table 3 shows Mullen cognitive development scores by suicidal ideation group. Children of mothers with emerging suicidal ideation had consistently lower mean T-scores across all child development domains, compared to the other groups.
In multivariable analysis, children of the women with emerging suicidal ideation had lower receptive language (aMD $-4.2 ; 95 \% \mathrm{CI}-7.2$ to $-1.2 ; \mathrm{p}=0.02$ ), visual reception (aMD $-4.4 ; 95 \% \mathrm{CI}-7.6$ to $-1.2 ; \mathrm{p}=0.04)$, and overall composite score (aMD $-6.1 ; 95 \% \mathrm{CI}-10.3$ to -1.8 ; $\mathrm{p}=0.03$ ) compared to the children of the reference group (Table 4). There was also an evidence of difference in the children's gross motor functioning by maternal suicidal ideation categories $(\mathrm{aMD}-5.2 ; 95 \% \mathrm{CI}-8.9$ to $-1.5 ; \mathrm{p}=0.01)$.

\section{Discussion}

This study aimed to explore maternal suicidal ideation in the presence of HIV and the association between such ideation over time with child cognitive development. Suicidal ideation in this group was high. Almost a third of the mothers 
Table 3 Mullen T-scores of children at 12 months follow-up by maternal suicidal ideation categories

\begin{tabular}{lllll}
\hline Mullen Scales (T-scores) & $\begin{array}{l}\text { Not suicidal at both baseline } \\
\text { and follow-up, } \mathrm{n}=287\end{array}$ & $\begin{array}{l}\text { Suicidal ideation at } \\
\text { baseline only, } \mathrm{n=66}\end{array}$ & $\begin{array}{l}\text { Suicidal ideation at } \\
\text { follow-up only, } \mathrm{n}=46\end{array}$ & $\begin{array}{l}\text { Suicidal at both } \\
\text { baseline and follow-up, } \\
\mathrm{n}=86\end{array}$ \\
Mean (SD) & Mean (SD) & Mean (SD) & Mean (SD) \\
\hline Expressive language & $45.4(9.2)$ & $46.1(9.6)$ & $42.2(8.3)$ & $44.3(10.0)$ \\
Receptive language & $46.1(9.6)$ & $46.8(9.4)$ & $41.3(12.2)$ & $44.1(10.6)$ \\
Fine motor & $41.9(11.2)$ & $42.3(10.9)$ & $37.3(9.5)$ & $40.5(9.8)$ \\
Gross motor & $49.9(11.3)$ & $50.7(11.3)$ & $44.0(11.8)$ & $48.3(11.4)$ \\
Visual reception & $42.5(10.9)$ & $42.7(11.3)$ & $37.2(10.7)$ & $41.7(11.2)$ \\
Early learning composite score & $88.7(15.2)$ & $89.4(14.3)$ & $80.5(14.9)$ & $86.2(15.8)$ \\
\hline
\end{tabular}

${ }^{a}$ Only measured in children aged $<36$ months at follow-up $(\mathrm{n}=397)$

Table 4 Regression models of child cognitive outcomes and maternal suicidal ideation

\begin{tabular}{|c|c|c|c|c|c|}
\hline & $\begin{array}{l}\text { No suicidal } \\
\text { ideation } \\
(\mathrm{n}=287)\end{array}$ & $\begin{array}{l}\text { Suicidal ideation at baseline } \\
\text { only }(n=66)\end{array}$ & $\begin{array}{l}\text { Suicidal ideation at } \\
\text { follow-up only }(n=46)\end{array}$ & $\begin{array}{l}\text { Suicidal at both } \\
\text { baseline and follow-up } \\
(\mathrm{n}=86)\end{array}$ & $\mathrm{p}$ value* \\
\hline & & $\begin{array}{l}\text { Adjusted mean difference } \\
\quad(95 \% \mathrm{CI})\end{array}$ & & & \\
\hline Expressive language & Ref & $1.23(-1.20$ to 3.67$)$ & $-2.27(-5.13$ to 0.59$)$ & $-0.26(-2.47$ to 1.95$)$ & 0.25 \\
\hline Receptive language & Ref & $1.12(-1.45$ to 3.69$)$ & $-4.18(-7.19$ to -1.16$)$ & $-1.49(-3.81$ to 0.82$)$ & 0.02 \\
\hline Fine motor & Ref & $0.70(-2.10$ to 3.49$)$ & $-3.45(-6.76$ to -0.15$)$ & $-0.87(-3.40$ to 1.65$)$ & 0.16 \\
\hline Gross motor $^{\mathrm{a}}$ & Ref & $2.16(-1.08$ to 5.40$)$ & $-5.18(-8.91$ to -1.46$)$ & $0.03(-3.08$ to 3.14$)$ & 0.01 \\
\hline Visual reception & Ref & $0.71(-1.99$ to 3.41$)$ & $-4.37(-7.56$ to -1.18$)$ & -0.37 ( -2.80 to 2.07$)$ & 0.04 \\
\hline Early learning composite score & Ref & $1.35(-2.28$ to 4.98$)$ & $-6.05(-10.34$ to -1.77$)$ & $-0.98(-4.26$ to 2.31$)$ & 0.03 \\
\hline
\end{tabular}

* Model adjusted for baseline Mullen scores, mother's age, clustering of trial sites and examiner

${ }^{a}$ Only measured in children aged $<36$ months at follow-up $(n=397)$

reported suicidal ideation at baseline, and this was reduced to $27.2 \%$ at endline. Mothers with suicidal ideation at baseline were more likely to be divorced or separated and suffer from elevated stress and depressive symptoms. In addition, household food insecurity levels were high in mothers with suicidal ideation. The results show evidence of an association between maternal suicidal ideation over time and child cognitive performance for this HIV affected sample. Children's gross motor, visual and receptive language abilities were the developmental domains most closely associated with maternal suicidal ideation. Additionally, children of mothers with emerging suicidal ideation tended to have lower cognitive scores across the developmental domains compared to the other groups.

The results here support previous research in which suicidal ideation was associated with marital status, food insecurity, maternal depression and stress [2, 4-6]. The lack of a support system or household food security may all contribute to the mother's mental well-being and the likelihood of suicidal thoughts or suicidal behaviour manifestation. Alternatively, suicidal ideation may mitigate against relationship formation and affect the ability to gather resources ensuring food security. Other studies in rural areas report being single or widowed, and being older in age is associated with increased food insecurity in PLWH [43]. Considering this was a rural population, there could also be high levels of food insecurity simply due to higher levels of poverty compared to urban areas, or limited availability of plots of land per family [44]. Suicidal ideation may be a result of the burden of these stressors and contemplating suicide a pathway to escape from them [45]. The findings suggest a clustering of negative life events such as HIV, and other life stressors result in elevated and chronic suicidal ideation. Although the direction of the effect between suicidal ideation and the factors discussed above cannot be definitively established, these associations point to both warning signs and intervention opportunities.

Similar to previous studies, maternal mental health was negatively associated with child development in the language and visual domains [13, 14]. It may be that mental health burdens and stress distract mothers from parenting and child stimulation reducing visual and verbal interactions and may affect the crucial child development steps. Deteriorating maternal mental health (i.e. emerging suicidal 
ideation) in particular seems to affect child cognition overall. Interestingly, the children of the improvers and reference group (i.e. no suicidal ideation) had similar scores on most of the developmental domains. Therefore, improving mental wellbeing or interruption of suicidal thoughts in mothers may potentially feed into improved maternal mental health and child outcomes over time. Furthermore, this study examines longitudinal changes in maternal suicidal ideation over 12 months for women living with HIV. The use of longitudinal analysis is pivotal in order to further understand the relationship between emerging maternal mental health issues and child development.

Some of the strengths of this study include a large sample size and utilization of previously validated assessment tools in similar settings such as the EPDS and SSQ-8. A study by Paris et al. (2009) examined the relationship between suicidality and mother-infant interactions using cross-sectional data [18]. Other studies in southern Africa have examined predictors of suicidal ideation in pregnancy/postpartum using cross-sectional data $[2,11,46]$. This study is the only one to our knowledge that investigates the impact of maternal suicidal ideation on child's cognitive development over time. This study adds useful insight to the literature on the role of maternal mental health on child development in the SSA context and highlights the impact of emerging maternal suicidal ideation on child cognitive development. The results here also provide valuable information on the characteristics of HIV positive mothers at risk of suicidal ideation in rural settings. Future studies examining maternal suicidal ideation and child development should utilize these socioeconomic predictors to identify the mothers who are at high risk for depression and suicidal ideation in similar settings. Findings from this study can also aid the development of suicide prevention and synergic intervention measures for HIV positive mothers and their children in a similar context.

Some limitations need to be taken into account. The data were collected in a trial and although there was no evidence of differences between trial arms, the changes over time may not reflect a true field situation. Although follow-up was in excess of $86 \%$, there may have been some attrition associated with key variables. Additionally, the Mullen scales use a USA reference group which is not ideal given the setting of the study in Zimbabwe. Locally validated scales and reference groups would have been preferable.

Despite these limitations, the data clearly show the high prevalence of suicidal ideation in HIV positive mothers, with close to a quarter of the sample recording suicidal ideation at baseline. Although this rate goes down over time, the rates at follow-up are still high and indicate an unmet mental health need. The results also show that maternal suicidal ideation can negatively affect child development domains, specifically their verbal and visual skills. Emerging maternal suicidal ideation, in particular, seems to affect child cognition.
Early child development is critical for later achievement. Given that a proportion of these children were HIV positive and all were HIV exposed there is already a concern for their cognitive development. This seems to be compounded by maternal suicidal ideation. Early identification and treatment of HIV positive mothers with suicidal ideation, can help improve their mental health, adherence to treatment and overall quality of life [24] and consequently result in long term gains for their children's development.

Acknowledgements We would like to thank all the participants and their children. We would also like to thank our various partners USAID-PEPFAR, the PEPFAR OVC Technical Working Group, CeSHHAR, and World Education Zimbabwe (Project Implementing Partner).

Funding The funding partners for the study are USAID-PEPFAR, funded under the Orphans and Vulnerable Children Special Initiative.

\section{Compliance with Ethical Standards}

Conflict of interest We declare no conflict of interest.

Ethical Approval All procedures performed in the trial (Registration Number PACTR201701001387209) were in accordance with the Ethical Standards of the Medical Research Council of Zimbabwe and Research Council of Zimbabwe (Approval Code MRCZ/A/1943), University College London (6789/002) and London School of Hygiene and Tropical Medicine (9912).

Informed Consent Informed consent was obtained from all individual participants included in the study.

Open Access This article is licensed under a Creative Commons Attribution 4.0 International License, which permits use, sharing, adaptation, distribution and reproduction in any medium or format, as long as you give appropriate credit to the original author(s) and the source, provide a link to the Creative Commons licence, and indicate if changes were made. The images or other third party material in this article are included in the article's Creative Commons licence, unless indicated otherwise in a credit line to the material. If material is not included in the article's Creative Commons licence and your intended use is not permitted by statutory regulation or exceeds the permitted use, you will need to obtain permission directly from the copyright holder. To view a copy of this licence, visit http://creativecommons.org/licenses/by/4.0/.

\section{References}

1. Sherr L, Lampe F, Fisher M, Arthur G, Anderson J, Zetler S, et al. Suicidal ideation in UK HIV clinic attenders. AIDS. 2008;22(13):1651-8.

2. Rodriguez VJ, Mandell LN, Babayigit S, Manohar RR, Weiss SM, Jones DL. Correlates of suicidal ideation during pregnancy and postpartum among women living with HIV in rural South Africa. AIDS Behav. 2018;22(10):3188-97.

3. Schlebusch L, Govender RD. Age, gender and suicidal ideation following voluntary HIV counseling and testing. Int J Environ Res Public Health. 2012;9(2):521-30. 
4. Kang CR, Bang JH, Cho S-I, Kim KN, Lee H-J, Ryu BY, et al. Suicidal ideation and suicide attempts among human immunodeficiency virus-infected adults: differences in risk factors and their implications. AIDS Care. 2016;28(3):306-13.

5. Egbe CO, Dakum PS, Ekong E, Kohrt BA, Minto JG, Ticao CJ. Depression, suicidality, and alcohol use disorder among people living with HIV/AIDS in Nigeria. BMC Public Health. 2017;17(1):542.

6. Bitew H, Andargie G, Tadesse A, Belete A, Fekadu WA-O, Mekonen TA-O. Suicidal ideation, attempt, and determining factors among HIV/AIDS patients, Ethiopia. Depress Res Treat. 2016;2016:8913160.

7. Schlebusch L, Vawda N. HIV-infection as a self-reported risk factor for attempted suicide in South Africa. Afr J Psychiatry (Johannesbg). 2010;13(4):280-3.

8. Patel V, Kleinman A. Poverty and common mental disorders in developing countries. Bull World Health Organ. 2003;81(8):609-15.

9. Kinyanda E, Hoskins S, Nakku J, Nawaz S, Patel V. The prevalence and characteristics of suicidality in HIV/AIDS as seen in an African population in Entebbe District, Uganda. BMC Psychiatry. 2012;12:63.

10. Wu DY, Munoz M, Espiritu B, Zeladita J, Sanchez E, Callacna $\mathrm{M}$, et al. Burden of depression among impoverished HIV-positive women in Peru. J Acquir Immune Defic Syndr. 2008;48(4):500-4.

11. Gebremariam EH, Reta MM, Nasir Z, Amdie FZ. Prevalence and associated factors of suicidal ideation and attempt among people living with HIV/AIDS at Zewditu Memorial Hospital, Addis Ababa, Ethiopia: a cross-sectional study. Psychiatry J. 2017;2017:1. https://doi.org/10.1155/2017/2301524.

12. Cooperman NA, Simoni JM. Suicidal ideation and attempted suicide among women living with HIV/AIDS. J Behav Med. 2005;28(2):149-56.

13. Mebrahtu H, Simms V, Chingono R, Mupambireyi Z, Weiss HA, Ndlovu P, et al. Postpartum maternal mental health is associated with cognitive development of HIV-exposed infants in Zimbabwe: a cross-sectional study. AIDS Care. 2018;30(sup2):74-82.

14. Murray SM, Familiar I, Nakasujja N, Winch PJ, Gallo JJ, Opoka $\mathrm{R}$, et al. Caregiver mental health and HIV-infected child wellness: perspectives from Ugandan caregivers. AIDS Care. 2017;29(6):793-9.

15. Black MM, Baqui AH, Zaman K, McNary SW, Le K, Arifeen SE, et al. Depressive symptoms among rural Bangladeshi mothers: implications for infant development. J Child Psychol Psychiatry Allied Discip. 2007;48(8):764-72.

16. Murphy DA, Marelich WD, Armistead L, Herbeck DM, Payne DL. Anxiety/stress among mothers living with HIV: effects on parenting skills and child outcomes. AIDS Care. 2010;22(12):1449-588.

17. Feldman R, Granat A, Pariente C, Kanety H, Kuint J, GilboaSchechtman E. Maternal depression and anxiety across the postpartum year and infant social engagement, fear regulation, and stress reactivity. J Am Acad Child Adolesc Psychiatry. 2009;48(9):919-27.

18. Paris R, Bolton R, Weinberg M. Postpartum depression, suicidality, and mother-infant interactions. Arch Womens Ment Health. 2009;12:309-21.

19. Lyons-Ruth K. Contributions of the mother-infant relationship to dissociative, borderline, and conduct symptoms in young adulthood. Infant Ment Health J. 2008;29(3):203-18.

20. Feldman R, Eidelman AI. Biological and environmental initial conditions shape the trajectories of cognitive and socialemotional development across the first years of life. Dev Sci. 2008;12(1):194-200.
21. Blanchette N, Smith M, Fernandes-Penney A, King S, Read S. Cognitive and motor development in children with vertically transmitted HIV infection. Brain Cogn. 2001;46:50-3.

22. Kerr SJ, Puthanakit T, Vibol U, Aurpibul L, Vonthanak S, Kosalaraksa $\mathrm{P}$, et al. Neurodevelopmental outcomes in HIV-exposeduninfected children versus those not exposed to HIV. AIDS Care. 2014;26(11):1327-35.

23. Van Rie A, Mupuala A, Dow A. Impact of the HIV/AIDS epidemic on the neurodevelopment of preschool-aged children in Kinshasa, Democratic Republic of the Congo. Pediatrics. 2008;122(1):e123-8.

24. January J, Chimbari MJ. Prevalence and factors associated with postnatal depression among women in two rural districts of Manicaland, Zimbabwe. S Afr J Psychiatry J Soc Psychiatrists S Afr. 2018;24:1176.

25. Verhey R, Gibson L, Brakarsh J, Chibanda D, Seedat S. Prevalence and correlates of probable post-traumatic stress disorder and common mental disorders in a population with a high prevalence of HIV in Zimbabwe. Eur J Psychotraumatol. 2018;9(1):1536286.

26. Willis N, Mavhu W, Wogrin C, Mutsinze A, Kagee A. Understanding the experience and manifestation of depression in adolescents living with HIV in Harare, Zimbabwe. PLoS ONE. 2018;13(1):e0190423.

27. January J, Chimbari MJ. Opportunities and obstacles to screening for perinatal depression among women in Zimbabwe: a narrative review of literature. S Afr J Psychiatry J Soc Psychiatrists S Afr. 2018;24:1127.

28. Chingono R, Mebrahtu H, Mupambireyi Z, Simms V, Weiss HA, Ndlovu P, et al. Evaluating the effectiveness of a multi-component intervention on early childhood development in paediatric HIV care and treatment programmes: a randomised controlled trial. BMC Pediatrics. 2018;15:222.

29. Coates J, Swindale A, Bilinsky P. Household food insecurity access scale (HFIAS) for measurement of food access: indicator guide (v3). Washington, DC: FHI 360/FANTA-2; 2007.

30. Chibanda D, Mangezi W, Tshimanga M, Woelk G, Rusakaniko P, Stranix-Chibanda L, et al. Validation of the Edinburgh Postnatal Depression Scale among women in a high HIV prevalence area in urban Zimbabwe. Arch Women's Ment Health. 2010;13(3):201-6.

31. Cox JL, Holden JM, Sagovsky R. Detection of postnatal depression. Development of the 10-item Edinburgh Postnatal Depression Scale. Br J Psychiatry. 1987;150:782-6.

32. Gibson J, McKenzie-McHarg K, Shakespeare J, Price J, Gray R. A systematic review of studies validating the Edinburgh Postnatal Depression Scale in antepartum and postpartum women. Acta psychiatr Scand. 2009;119(5):350-64.

33. McCabe-Beane JE, Segre LS, Perkhounkova Y, Stuart S, O'Hara MW. The identification of severity ranges for the Edinburgh Postnatal Depression Scale. J Reprod Infant Psychol. 2016;34(3):293-303.

34. Gausia K, Fisher C, Ali M, Oosthuizen J. Antenatal depression and suicidal ideation among rural Bangladeshi women: a community-based study. Arch Women's Ment Health. 2009;12(5):351.

35. da Silva RA, da Costa OL, Jansen K, da Silva Moraes IG, de Mattos Souza LD, Magalhães P, et al. Suicidality and associated factors in pregnant women in Brazil. Community Ment Health J. 2012;48(3):392-5.

36. Dørheim Ho-Yen S, Tschudi Bondevik G, Eberhard-Gran M, Bjorvatn $\mathrm{B}$. The prevalence of depressive symptoms in the postnatal period in Lalitpur District, Nepal. Acta Obstet Gynecol Scand. 2010;85(10):1186-92.

37. Rochat TJ, Bland RM, Tomlinson M, Stein A. Suicide ideation, depression and HIV among pregnant women in rural South Africa. Health. 2013;5(3A):650-61.

38. Abidin RR. Parenting stress index: professional manual. 3rd ed. Odessa: Psychological Assessment Resources, Inc.; 1995. 
39. Patel V, Simunyu E, Gwanzura F, Lewis G, Mann A. The Shona Symptom Questionnaire: the development of an indigenous measure of common mental disorders in Harare. Acta Psychiatr Scand. 1997;95(6):469-75.

40. Mullen EM. Mullen scales of early learning. Circle Pines: AGS; 1995.

41. Boivin MJ, Nakasujja N, Sikorskii A, Opoka RO, Giordani B. A randomized controlled trial to evaluate if computerized cognitive rehabilitation improves neurocognition in Ugandan children with HIV. AIDS Res Hum Retrovir. 2016;32(8):743-55.

42. Akshoomoff N. Use of the Mullen scales of early learning for the assessment of young children with autism spectrum disorders. Child Neuropsychol J Norm Abnorm Dev Child Adolesc. 2006;12(4-5):269-77.

43. Nagata JM, Magerenge RO, Young SL, Oguta JO, Weiser SD, Cohen CR. Social determinants, lived experiences, and consequences of household food insecurity among persons living with HIV/AIDS on the shore of Lake Victoria, Kenya. AIDS Care. 2012;24(6):728-36.
44. Mamlin J, Kimaiyo S, Lewis S, Tadayo H, Jerop FK, Gichunge $\mathrm{C}$, et al. Integrating nutrition support for food-insecure patients and their dependents into an HIV care and treatment program in Western Kenya. Am J Public Health. 2009;99(2):215-21.

45. Dabaghzadeh F, Jabbari F, Khalili H, Abbasian L. Associated factors of suicidal thoughts in HIV-positive individuals. Iran J Psychiatry. 2015;10(3):185-91.

46. Rodriguez VJ, Cook RR, Peltzer K, Jones DL. Prevalence and psychosocial correlates of suicidal ideation among pregnant women living with HIV in Mpumalanga Province, South Africa. AIDS Care. 2017;29(5):593-7.

Publisher's Note Springer Nature remains neutral with regard to jurisdictional claims in published maps and institutional affiliations. 